\title{
Epidemiological profile of patients with congenital and gestational syphilis in a city in the State of São Paulo, Brazil
}

Taiza Maschio-Lima 1

(iD) https://orcid.org/0000-0001-6744-2784

lara Lúcia de Lima Machado 2

iD https://orcid.org/0000-0002-9960-0940

João Paulo Zen Siqueira 3

https://orcid.org/0000-0002-5807-9204

Margarete Teresa Gottardo Almeida 4

D https://orcid.org/0000-0002-8665-9126

\footnotetext{
1,3,4 Laboratório de Microbiologia. Departamento de Doenças Dermatológicas, Infecciosas e Parasitárias. Faculdade de Medicina de São José do Rio Preto. Av. Brigadeiro Faria Lima, 5416. Vila São Pedro. São José do Rio Preto, SP, Brasil. CEP: 15.090-000. E-mail: taizamlima@yahoo.com.br

2 Departamento de Vigilância em Saúde. Secretária Municipal de Saúde de São José do Rio Preto/SP.
}

\begin{abstract}
Objectives: to assess the epidemiological profile of congenital and syphilis during pregnancy in residents of São José do Rio Preto in São Paulo State.

Methods: ecological study of the epidemiological profile of patients with congenital and gestational syphilis, based on the Sistema de Informação de Agravos de Notificação (Information System for Notifiable Diseases) from 2007 to 2016.

Results: there were 396 cases of syphilis reported in pregnant women and 290 of congenital syphilis. In 2016, the rate of detecting syphilis in pregnant women was 13.2 cases $/ 1,000$ live births, while congenital syphilis the incidence rate was 6.5 cases/1,000 live births. For gestational syphilis, 54\% of the diagnosis was performed in $2^{\text {nd }}$ or 3 rd trimester and $85 \%$ were reported at the primary care. Adequate treatment for pregnant women occurred in $96 \%$ of the notifications with $52 \%$ of partners treated. In congenital syphilis, $82 \%$ of the mothers underwent prenatal care. However, $94 \%$ of the pregnant women were treated inadequately while $82 \%$ of the partners did not receive any treatment.

Conclusions: there has been an increase in the number of cases of gestational syphilis in pregnant women and a decrease in the cases of congenital syphilis from 2014. These results showed that the goal of 0.5 case/1,000 live births proposed by World Health Organization is still far from being achieved in this city.

Key words Vertical transmission of infectious diseases, Pregnant women, Epidemiological surveillance, Notifiable diseases
\end{abstract}

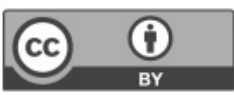




\section{Introduction}

Syphilis is an infectious disease with chronic evolution and often asymptomatic, caused by the Treponema pallidum bacterium. Transmission occurs by sexual intercourse without any protection, vertically or by contaminated blood transfusion. 1

It is estimated that over 11 million new cases of syphilis occur each year worldwide, with high incidence rates specially in Latin America, Africa and Asia. ${ }^{2}$ In Brazil, the disease constitutes as a serious public health problem, especially in the maternal and child population. 3,4

In Brazil, between 2007 and 2016, there has been an increase in the number of notifications and epidemiological rates of syphilis at pregnancy and congenital syphilis. In pregnant women, the detection rate was 2.5 cases/1,000 live births in 2007 to 12.4 cases/1,000 live births in 2016. For congenital syphilis, the incidence rate was 1.9 cases/1,000 live births in 2007 and increased to 6.8 cases/1,000 live births in 2016.5

During 2007 to 2011 , there were 49,166 cases of syphilis in pregnant women and 33,763 cases of congenital syphilis. From 2012 to 2016, there was a considerable increase in syphilis cases in pregnant women in the country, totaling 137,497 cases. The same was observed for congenital syphilis, with 226,460 cases that occurred in this period. 5 Only in $2016,37,436$ cases of syphilis in pregnant women and 20,474 cases of congenital syphilis were reported, causing the death of 185 children under one year of age. 6

The elimination of congenital syphilis is one of the goals proposed by the World Health Organization (WHO) expected from the Millennium Development Goals (MDG), stipulating an incidence rate of 0.5 cases per 1,000 live births. 7,8 Syphilis is a notifiable disease, being reported in Brazil since 1986. However, in pregnant women, the notification is mandatory since 2005, and for congenital syphilis, since 2010.9

Syphilis in pregnant women is treatable; consequently, congenital syphilis can be prevented. Its occurrence is indicative of failures in the prenatal care, diagnosis, or treatment. 10 Transmission to the fetus can have serious implications and it is important that cases of syphilis in pregnant women are detected and treated in a timely manner, together with their sexual partners. ${ }^{11}$

Given the impact of syphilis in public health and the increasing number of cases, it is extremely important that the cities know the real occurrence of the disease in their population so that prevention and control actions can be taken. Therefore, the objective of this study was to assess the epidemiological profile of mandatory notifications of congenital syphilis in pregnant women registered and living in the city in São José do Rio Preto, Brazil, from 2007 to 2016 .

\section{Methods}

This is an ecological study, using data contained in the Sistema de Informação de Agravos de Notificação (Sinan) (Information System for Notifiable Diseases) from mandatory notifications of syphilis cases in pregnant women and congenital syphilis in residents in São José do Rio Preto, Brazil, from January 1, 2007 to December 31, 2016.

The Sistema de Informação de Nascidos Vivos (Sinasc) (Live Birth Information System) was used to retrieve the number of live births in this city during the study period and to calculate incidence and detection rates. All the data from Sinan and Sinasc were collected at the Vigilância Epidemiológica da Secretaria Municipal de Saúde (Epidemiological Surveillance Service at the Municipal Secretary of Health).

Cases of syphilis in pregnant women and congenital syphilis cases were defined according to precepts of the Ministry of Health and data presented from the Sinan notification/investigation forms. Regarding to pregnant women, cases are notified during prenatal care when presenting clinical evidence or positive serology.

Cases of congenital syphilis are notified for newborns, stillbirths or miscarriages from women with untreated or improperly treated syphilis. In addition, cases of children under 13 years old with clinical, serological or microbiological evidence of infection are also notified. ${ }^{7}$

In this study, all syphilis notification forms from residents in São José do Rio Preto in the period of analysis were included. All forms were analyzed, including the ones with missing information. Those cases are mentioned in Results and in Discussion.

Thereby, 396 notifications forms of syphilis in pregnant women and 290 notifications of congenital syphilis were analyzed. The assessed parameters were chosen according to the greatest epidemiological impact and to the literature on this subject. Firstly, the data was exported from Sinan and tabulated using the TabWin ${ }^{\circledR}$ software. Epi Info ${ }^{\circledR}$ and Microsoft Office Excel ${ }^{\circledR}$ were used for calculation of distribution free statistics and epidemiological rates.

The detection rate of syphilis in pregnant women 
was calculated by the number of reported cases per year divided by the number of live births in the same year/place and multiplied by 1,000 . To calculate the incidence rate of congenital syphilis, the number of new cases per year was used, divided by the number of live births of the same year/place and multiplied by 1,000 .

In the notifications of syphilis in pregnant women, the analyzed variables were: sociodemographic characteristics (age, race, schooling, and occupation), health unit which notified the case, clinical classification of the disease, and treatment of pregnant women and partners. For congenital syphilis, the mother's epidemiological antecedents (prenatal care and time of diagnosis), the mother's and partners' treatment, the child's laboratory tests and clinical information, treatment, and evolution were considered.

The forms utilized in this research did not present the names of the individuals; therefore, their identity was kept confidential. There was no need for the Informed Consent Form. This project was approved by the Secretaria Municipal de Saúde (Municipal Secretary of Health) and the Ethics Committee in Research of the School of Medicine of São José do Rio Preto (FAMERP) under the document number 2.106.872 (CAAE: 68727317.9.0000.5415).

\section{Results}

Between 2007 and 2016, 396 cases of syphilis were reported from pregnant women with a clear increase in the number of notifications, from 10 cases $(2.5 \%)$ in 2007 to 71 cases (18\%) in 2016. Consequently, there was an increase in the detection rate of the disease in pregnant women, with 13.2 cases/1,000 live births in 2016, the highest rate in the studied period (Table 1). Regarding the sociodemographic profiles from the pregnant women, there was a higher occurrence in white women $(57 \%)$, between the ages of 20 to 29 years old (55\%), with incomplete elementary schooling (27\%), and housewives (46\%) (Table 2).

From the reports of syphilis in pregnant women, $338(85 \%)$ were performed at the primary care units, and $54 \%$ of the pregnant women were notified in the $2^{\text {nd }}$ or $3^{\text {rd }}$ trimester of pregnancy. The primary stage of the disease was registered in $38 \%$ of the pregnant women and, in most cases (97\%), the treatment was performed, using benzathine penicillin in three doses was the most common therapeutic approach (Table 2).

In relation to the pregnant women's partners, $52 \%$ chose to receive the treatment, and $38 \%$ did not. In $10 \%$ of the case, the information was not available. Among the reasons for not receiving the treatment, there are facts that the partners were not in a relationship with the pregnant women anymore $(10 \%)$, and non-attendance of the partner at the Basic Health Units (6\%). However, $62 \%$ of the notifications were ignored data (Table 2).

Concerning congenital syphilis, 290 cases were registered with the highest incidence in 2014 (63 cases, 22\%), corresponding to 11.1 cases/1,000 live births. The incidence rate increased between 2007 and 2014. However, in 2015 and 2016 the rates were lower, respectively, 6.0 and 6.5 cases/1,000 live births (Table 1).

The epidemiological record of congenital syphilis showed that $82 \%$ of the pregnant women received prenatal care, and $63 \%$ of them were diag-

Table 1

Cases of congenital syphilis, cases of syphilis in pregnant women, detection rate of gestational syphilis and incidence rate of congenital syphilis, according to year of diagnosis. São José do Rio Preto, Brazil, 2007-2016.

\begin{tabular}{lcccccccccc}
\hline & 2007 & 2008 & 2009 & 2010 & 2011 & 2012 & 2013 & 2014 & 2015 & 2016 \\
\hline $\begin{array}{l}\text { Gestational syphilis } \\
\mathrm{N}^{+}\end{array}$ & 10 & 13 & 15 & 34 & 40 & 46 & 58 & 46 & 63 & 71 \\
$\%$ & 2.53 & 3.28 & 3.79 & 8.59 & 10.10 & 11.62 & 14.65 & 11.62 & 15.91 & 17.93 \\
DR GS & 2.1 & 2.6 & 2.9 & 6.5 & 7.7 & 8.6 & 10.8 & 8.1 & 11.1 & 13.2 \\
Congenital syphilis & & & & & & & & & & \\
$\mathrm{N}^{*}$ & 6 & 3 & 4 & 19 & 30 & 41 & 55 & 63 & 34 & 35 \\
$\%$ & 2.07 & 1.03 & 1.38 & 6.55 & 10.34 & 14.14 & 18.97 & 21.72 & 11.72 & 12.07 \\
IR CS** & 1.2 & 0.6 & 0.8 & 3.6 & 5.7 & 7.7 & 10.3 & 11.1 & 6.0 & 6.5 \\
\hline
\end{tabular}

† Total number of cases of syphilis in pregnant woman corresponds to 396 ;

₹ Detection rate of gestational syphilis:

* Total number of cases of congenital syphilis corresponds to 290;

** Incidence rate of congenital syphilis. 
Table 2

Sociodemographic, clinical, and epidemiological characteristics of notified pregnant women. São José do Rio Preto, Brazil, 2007-2016.

\begin{tabular}{|c|c|c|}
\hline Characteristics & $N=396$ & $\%$ \\
\hline \multicolumn{3}{|l|}{ Sociodemographic } \\
\hline \multicolumn{3}{|l|}{ Age group (years) } \\
\hline$\leq 19$ & 92 & 23.23 \\
\hline $20-29$ & 217 & 54.80 \\
\hline$\geq 30$ & 87 & 21.97 \\
\hline \multicolumn{3}{|l|}{ Race } \\
\hline Caucasian & 227 & 57.32 \\
\hline Mixed & 115 & 29.04 \\
\hline Black & 40 & 10.10 \\
\hline Unknown/blank & 14 & 3.54 \\
\hline \multicolumn{3}{|l|}{ Schooling } \\
\hline Unknown/blank & 66 & 16.67 \\
\hline Illiterate & 2 & 0.51 \\
\hline Incomplete elementary degree & 108 & 27.27 \\
\hline Elementary degree & 35 & 8.84 \\
\hline Incomplete high school degree & 81 & 20.45 \\
\hline High school degree & 91 & 22.98 \\
\hline Incomplete higher education degree & 5 & 1.26 \\
\hline Higher education degree & 8 & 2.02 \\
\hline \multicolumn{3}{|l|}{ Occupation } \\
\hline Housewife & 182 & 45.96 \\
\hline Student & 13 & 3.28 \\
\hline Receptionist & 12 & 3.03 \\
\hline Housekeeper & 12 & 3.03 \\
\hline Cook & 3 & 0.76 \\
\hline Manicure & 6 & 1.52 \\
\hline Sex worker & 7 & 1.77 \\
\hline Saleswoman & 4 & 1.01 \\
\hline Unemployed & 3 & 0.76 \\
\hline Administrative assistant & 3 & 0.76 \\
\hline Others & 27 & 6.82 \\
\hline Unknown/blank & 124 & 31.31 \\
\hline \multicolumn{3}{|l|}{ Clinical and epidemiological } \\
\hline \multicolumn{3}{|l|}{ Notifying health unit } \\
\hline Primary care & 338 & 85.35 \\
\hline Tertiary care & 34 & 8.59 \\
\hline Specialized care & 22 & 5.56 \\
\hline City Secretary of Health & 2 & 0.51 \\
\hline \multicolumn{3}{|l|}{ Gestational trimester } \\
\hline 1st trimester & 163 & 41.16 \\
\hline $2^{\text {nd }}$ trimester & 134 & 33.84 \\
\hline 3rd trimester & 80 & 20.20 \\
\hline Unknown gestational age & 10 & 2.53 \\
\hline Unknown/blank & 9 & 2.27 \\
\hline \multicolumn{3}{|l|}{ Clinical stage of the disease } \\
\hline Unknown/blank & 89 & 22.47 \\
\hline Primary & 149 & 37.63 \\
\hline Secondary & 36 & 9.09 \\
\hline Tertiary & 40 & 10.10 \\
\hline Latent & 82 & 20.71 \\
\hline
\end{tabular}


Sociodemographic, clinical, and epidemiological characteristics of notified pregnant women. São José do Rio Preto, Brazil, 2007-2016.

\begin{tabular}{lcc}
\hline Characteristics & $\mathrm{N}=396$ & $\%$ \\
\hline Treatment for pregnant women & 383 & 96.72 \\
Yes & 12 & 3.03 \\
No & 1 & 0.25 \\
Unknown/blank & & 52.27 \\
Treatment for the partner & 207 & 38.38 \\
Yes & 152 & 9.34 \\
No & 37 & 61.62 \\
Unknown/blank & & 10.10 \\
Reason the partner did not treat & & 6.31 \\
Unknown/blank & 244 & 5.05 \\
No relation with the pregnant woman & 40 & 1.01 \\
Partner did not attend & 25 & 0.51 \\
Partner with non-reactive serology & 20 & 15.40 \\
Partner was not notified by the health service & 4 & 2 \\
Partner refused treatment & 61 & \\
Other reasons & & \\
\hline
\end{tabular}

nosed during this period. However, in $34 \%$ of the cases, the disease was only identified at the moment of giving birth or at curettage. In 274 cases (94\%), the treatment for pregnant woman was considered inappropriate or not performed, and $82 \%$ of the partners were not treated (Table 3 ).

Nontreponemal blood tests for newborns were reactive in $61 \%$ of cases and nonreactive in $20 \%$ (Table 3). In cerebrospinal fluid (CSF) samples, most were non-reactive $(\mathrm{N}=175)$, but $9 \%$ of cases presented changes in CSF analysis. Bone complications were present in $14 \%$ of the cases.

The most common treatment scheme for newborns was with crystalline penicillin G, 100,000 to $150,000 \mathrm{UI} / \mathrm{kg} /$ day, for 10 days $(44 \%)$, followed by penicillin $\mathrm{G}$ procaine, $50,000 \mathrm{UI} / \mathrm{kg} /$ day, for 10 days $(31 \%)$. The outcomes of congenital syphilis cases were classified as: alive (83\%), abortion (9\%), stillbirth (5\%), death from syphilis $(1 \%)$ and death from other causes $(1 \%)$ (Table 3$)$.

\section{Discussion}

According to the national and state data from 2007 to 2016 , there was an increase in the number of syphilis notifications in pregnant women, both in the city object of the study and Brazil..$^{5}$ Nevertheless, in 2016, São José do Rio Preto exhibited a syphilis detection rate in pregnant women of 13.2 cases/1,000 live births, above the national and state of São Paulo rates, respectively, 12.4 and 12.9 cases/1,000 live births, in the same year. 6

An increased number of notifications of syphilis in pregnant women may be associated with several factors, such as a reduction of underreporting, access of pregnant women to prenatal care, and effective diagnosis. 13,14 Plans and strategies developed by the Sistema Único de Saúde (SUS) (Public Health System), such as the "Rede Cegonha" (Stork Network) and the implementation of rapid tests for screening syphilis in the primary care, improving the diagnosis and increasing the detection rate of syphilis in pregnant women. ${ }^{4}$ In this study, $85 \%$ of the pregnant women were notified in the primary care. However, most pregnant women (54\%) were diagnosed only during the $2^{\text {nd }}$ and $3^{\text {rd }}$ trimesters of pregnancy, indicating that improvements in early diagnostic actions are still needed.

In relation to the pregnant women profiles, there was a predominance of women aged 20 to 29 years old (55\%), similar as to São Paulo state, Brazil, and other locations, maybe because it is the most intense sexual life phase. These results highlight the need of actions focused on health education, safer sex practices, and family planning.

Regarding race and schooling, results were comparable to the data from São Paulo state.6,18 Higher frequency was observed for Caucasian pregnant women $(57 \%)$ with incomplete elementary schooling (27\%). As for occupation, $46 \%$ of the 
Characteristics of prenatal care and treatment for the pregnant woman and partner, clinical and laboratory aspects of the child, and evolution of the cases of congenital syphilis. São Jose do Rio Preto, Brazil, 2007-2016.

\begin{tabular}{|c|c|c|}
\hline Characteristics & $\mathrm{N}=396$ & $\%$ \\
\hline \multicolumn{3}{|l|}{ Background of pregnant woman and partner } \\
\hline \multicolumn{3}{|l|}{ Prenatal care } \\
\hline Yes & 237 & 81.72 \\
\hline No & 53 & 18.28 \\
\hline \multicolumn{3}{|l|}{ Diagnosis of the pregnant woman } \\
\hline During prenatal care & 183 & 63.10 \\
\hline During birth/curettage & 98 & 33.79 \\
\hline After birth & 8 & 2.76 \\
\hline Not performed & 1 & 0.34 \\
\hline \multicolumn{3}{|l|}{ Partner treated } \\
\hline No & 239 & 82.41 \\
\hline Yes & 31 & 10.69 \\
\hline Unknown/blank & 20 & 6.90 \\
\hline \multicolumn{3}{|l|}{ Treatment for pregnant women } \\
\hline Inadequate/Not treated & 274 & 94.48 \\
\hline Adequate & 12 & 4.14 \\
\hline Unknown/blank & 4 & 1.38 \\
\hline \multicolumn{3}{|l|}{ Child's clinic and laboratorial } \\
\hline \multicolumn{3}{|l|}{ Clinical diagnosis } \\
\hline Asymptomatic & 207 & 71.38 \\
\hline Symptomatic & 23 & 7.93 \\
\hline Not applicable & 33 & 11.38 \\
\hline Unknown/blank & 27 & 9.31 \\
\hline \multicolumn{3}{|l|}{ Non-Treponemal test (blood) } \\
\hline Reagent & 178 & 61.38 \\
\hline Not reagent & 59 & 20.34 \\
\hline Not performed & 32 & 11.03 \\
\hline Unknown/blank & 21 & 7.24 \\
\hline \multicolumn{3}{|l|}{ Non- Treponemal test (cerebrospinal fluid) } \\
\hline Reagent & 7 & 2.41 \\
\hline Not reagent & 175 & 60.34 \\
\hline Not performed & 81 & 27.93 \\
\hline Unknown/blank & 27 & 9.31 \\
\hline \multicolumn{3}{|l|}{ Cerebrospinal fluid alterations } \\
\hline No & 157 & 54.14 \\
\hline Yes & 26 & 8.97 \\
\hline Not performed & 70 & 24.14 \\
\hline Unknown/blank & 37 & 12.76 \\
\hline \multicolumn{3}{|l|}{ Long bones alterations } \\
\hline No & 184 & 63.45 \\
\hline Yes & 42 & 14.48 \\
\hline Not performed & 39 & 13.45 \\
\hline Unknown/blank & 25 & 8.62 \\
\hline \multicolumn{3}{|l|}{ Child's treatment scheme and outcome } \\
\hline \multicolumn{3}{|l|}{ Newborn Treatment } \\
\hline Crystalline Penicillin G 100.000-150.000Ul/kg/day, for 10 days & 127 & 43.79 \\
\hline Penicillin G Procaine $50.000 \mathrm{UI} / \mathrm{kg} /$ day, for 10 days & 91 & 31.38 \\
\hline Penicillin G Benzatin $50.000 \mathrm{UI} / \mathrm{kg} /$ day, single dose & 9 & 3.10 \\
\hline Other scheme & 7 & 2.41 \\
\hline Not performed & 36 & 12.41 \\
\hline Unknown/blank & 20 & 6.90 \\
\hline
\end{tabular}


Characteristics of prenatal care and treatment for the pregnant woman and partner, clinical and laboratory aspects of the child, and evolution of the cases of congenital syphilis. São Jose do Rio Preto, Brazil, 2007-2016..

\begin{tabular}{lcc}
\hline Characteristics & $\mathrm{N}=\mathbf{3 9 6}$ & $\%$ \\
\hline Outcome & & 83.10 \\
Alive & 241 & 1.38 \\
Death from syphilis & 4 & 0.69 \\
Death of other cause & 2 & 8.97 \\
Abortion & 26 & 4.83 \\
Stillbirth & 14 & 1.03 \\
Unknown/blank & 3 & \\
\hline
\end{tabular}

pregnant women were referred to as housewives, in agreement to other studies, 14,15 although this information is often overlooked in the forms.

The maternal profiles observed in this study reflects the social context of syphilis, affecting individuals with higher social vulnerabilities, since most of women are not employed and do not have degree. Other researches point out that this context is related to social exclusion, the lack of prenatal care and difficulty to have access to information and schooling. 12,15,17 Thus, educational actions should focus on this population group, beginning at school age.

The incidence rates of congenital syphilis in Brazil and São Paulo state showed a linear and constant increase over the analyzed period (1.9 and 1.4 cases/1,000 live births in 2007, and 6.8 and 5.8 cases/1,000 live births in 2016, respectively). ${ }^{6}$ In comparison, the incidence rate in São José do Rio Preto was 1.2 cases/1,000 live births in 2007 and reached its peak in 2014 (11.1 cases/1,000 live births). However, in 2015 and 2016, there was a decrease in the incidence rate ( 6.0 to 6.5 cases $/ 1,000$ live births, respectively). It is suggested that this decrease may be the result of the efforts on prevention and early diagnosis of pregnant women in the city.

In contrast, some surveillance actions implemented by SUS may explain the high number of notifications of congenital syphilis, despite the decrease in recent years in this city. For example, improvement in diagnosis and mandatory serological tests at the moment of birth. However, there are still deficiencies in the primary care, especially in prenatal care, which also contribute to the increase in reported cases. Nonetheless, there are still deficiencies in the primary care, especially in prenatal care, which are also responsible for the increase in the number of cases. 15 These deficiencies can be noted by the fact that $34 \%$ of mothers whose newborns were notified for congenital syphilis were only diagnosed at birth. Similar data is reported in other areas in Brazil.19-21

Analyzing the treatment of the pregnant women, in $94 \%$ of the cases it was considered inadequate and, in $82 \%$ of the cases, their partners were not even treated. This is frequently reported in the literature. 14,19,22,23 Inadequate treatment of pregnant women and their partners is a key point in the occurrence of congenital syphilis. Despite that, still lacks efforts from public agencies to overcome this problem.

Epidemiological indicators are essential for carrying out surveillance actions and they should be analyzed in many contexts. A low number of cases of congenital syphilis does not necessarily indicate that vertical transmission is under control, since the disease may be occurring but without being notified. On the other hand, elevated numbers may suggest failures in the healthcare process, such as difficulties to access the services and inadequate treatment of pregnant women and their partners. 13,22,23

Elimination of congenital syphilis can be achieved by the cities through projects in line with the proposals of WHO. Actions for prevention, addressed at women of childbearing age, breaking the chain of acquired syphilis, consolidation of prenatal care conducts, and follow-up of pregnant women are crucial for controlling the disease.

Other strategies may include: training health professionals, sexually transmitted infections prevention campaigns, and raising awareness about this problem. In addition, health surveillance programs are important to reduce the underreported cases. 


\section{Authors' contribution}

Conception and planning of the study: TML, ILLM, MTGA. Data collection, analyses and interpretation: TML, ILLM, JPZS, MTGA. Preparation and revision of the manuscript: TML, JPZS, MTGA. All authors have approved the final version of the manuscript and are publicly responsible for the content of the article.

\section{References}

1. Tabisz L, Bobato CT, Carvalho MFU, Takimura M, Reda S, Pundek MRZ. Sífilis, uma doença reemergente. Rev Med Res. 2012; 14 (3): 165-72.

2. Lafeta KRG, Junior HM, Silveira MF, Paranaiba LMR Sífilis materna e congênita, subnotificação e difícil controle. Rev Bras Epidemiol. 2016; 19 (1): 63-74.

3. PAHO (Pan American Health Organization). Elimination of Mother-to-Child Transmission of HIV and Syphilis in the Americas - Update 2015. Washington, DC; 2015.

4. Brasil. Ministério da Saúde. Comissão Nacional de Incorporação de Tecnologias no SUS. Protocolo Clínico e Diretrizes Terapêuticas Infecções Sexualmente Transmissíveis. Brasília, DF; 2015.

5. Brasil. Ministério da Saúde. Secretaria de Vigilância em Saúde. Departamento de DST, Aids e Hepatites Virais. Boletim Epidemiológico - Sífilis. Brasília, DF; 2016

6. Brasil. Ministério da Saúde. Secretaria de Vigilância em Saúde. Departamento de DST, Aids e Hepatites Virais. Boletim Epidemiológico - Sífilis Brasília, DF; 2017.

7. São Paulo. Secretaria de Estado da Saúde. Centro de Controle de Doenças. Programa Estadual de DST/Aids e Centro de Referência e Treinamento DST/Aids. Guia de bolso para o manejo da sífilis em gestantes e sífilis congênita. São Paulo: Secretaria de Estado da Saúde; 2014.

8. Chinazzo LK, de Leon CA. Perfil clínico e epidemiológico da sífilis congênita na unidade de internação de um hospital universitário. Bol Cient Pediatr. 2015; 4 (3): 65-9.

9. Lima MG, Santos RFR, Barbosa GJA, Ribeiro GS. Incidência e fatores de risco para sífilis congênita em Belo Horizonte, Minas Gerais, 2001-2008. Ciênc Saúde Coletiva. 2013; 18 (2): 499-506.

10. Nonato SM, Melo APS, Guimarães MDC. Syphilis in pregnancy and factors associated with congenital syphilis in Belo Horizonte-MG, Brazil, 2010-2013. Epidemiol Serv Saúde. 2015; 24 (4): 681-94.

11. Brasil. Ministério da Saúde. Comissão Nacional de Incorporação de Tecnologias no SUS. Protocolo Clínico e Diretrizes Terapêuticas Infecções Sexualmente Transmissíveis. Brasília, DF; 2015.

Received on February 13, 2019

Final version presented on June 19, 2019

Approved on August 1, 2019
12. Domingues RM, Szwarcwald CL, Souza Junior PR, Leal MC. Prevalence of syphilis in pregnancy and prenatal syphilis testing in Brazil: birth in Brazil study. Rev Saúde Pública. 2014; 48: 766-74

13. Domingues RMSM, Hartz ZMA, Leal MC. Avaliação das ações de controle da sífilis e do HIV na assistência pré-natal da rede pública do município do Rio de Janeiro, Brasil. Rev Bras Saúde Mater Infant. 2012; 12 (3): 269-80.

14. Araújo CL, Shimizu HE, Sousa AIA, Hamann EM. Incidência da sífilis congênita no Brasil e sua relação com a estratégia saúde da família. Rev Saúde Pública. 2012 Nov; 46 (3): 479-86

15. Nunes JT, Gomes KRO, Rodrigues MTP, Mascarenhas MDM. Qualidade da assistência pré-natal no Brasil: revisão de artigos publicados de 2005 a 2015. Cad Saúde Coletiva. 2016; 24 (2): 252-61.

16. Araujo EC, Costa KSG, Silva RS, Azevedo VNG, Lima FAS. Importância do pré-natal na prevenção da Sífilis Congênita. Rev Para Med. 2006; 20 (1): 47-51.

17. Saraceni V, Pereira GFM, Silveira MF, Araujo MAL, Miranda AE. Vigilância epidemiológica da transmissão vertical da sífilis: dados de seis unidades federativas no Brasil. Rev Panam Salud Publica. 2017; 41: e44.

18. Lima VC, Mororó RM, Martins MA, Ribeiro SM, Linhares MSC. Perfil epidemiológico dos casos de sífilis congênita em um município de médio porte no nordeste brasileiro. J Health Biol Sci. 2017; 5 (1): 56-61.

19. Cavalcante PAM, Pereira RBL, Castro JGD. Syphilis in pregnancy and congenital syphilis in Palmas, Tocantins State, Brasil, 2007-2014. Epidemiol Serv Saúde. 2017; 26 (2): $1-10$.

20. Carvalho IS, Brito RS. Sífilis congênita no Rio Grande do Norte: estudo descritivo do período 2007-2010. Epidemiol Serv Saúde. 2014; 23 (2): 287-94.

21. Padovani C, Oliveira RR, Pelloso SM. Sífilis na gestação: associação das características maternas e perinatais em região do sul do Brasil. Rev Latino-Am Enfermagem. 2018; 26: e3019.

22. Campos ALA, Araujo MAL, Melo SP, Gonçalves MLC Epidemiologia da sífilis gestacional em Fortaleza, Ceará, Brasil: um agravo sem controle. Cad Saúde Pública. 2010; 26 (9): 1747-55.

23. Rocha RPS, Terças ACP, Nascimento VF, Silva JH, Gleriano JS. Análise do perfil epidemiológico de sífilis nas gestantes e crianças, em Tangará da Serra, de 2007 a 2014. Rev Norte Mineira Enf. 2016; 5 (2): 03-21. 